\title{
Analysis of Prognostic and Therapeutic Values of Drug Resistance-Related Genes in the Lung Cancer Microenvironment
}

\section{Liang Zhu}

Tongji University

\section{Peixin Chen}

Tongji University

\section{Hao Wang}

Tongji University

\section{Lishu Zhao}

Tongji University

Haoyue Guo

Tongji University

\section{Minlin Jiang}

Tongji University

\section{Sha Zhao}

Tongji University

\section{Wei Li}

Tongji University

Jun Zhu

Tongji University

Jia Yu

Tongji University

Jiawei Dai

SJTU-Yale Joint Center for Biostatistics and Data Science, Department of Bioinformatics and Biostatistics, School of Life Sciences and Biotechnology, Shanghai Jiao Tong University, Shanghai, China Yayi He ( $\square 2250601 @ q q . c o m$ )

Tongji University

\section{Research Article}

Keywords: lung cancer, prognosis, biomarkers, bioinformatics analysis, tumor microenvironment

Posted Date: August 3rd, 2021 
DOI: https://doi.org/10.21203/rs.3.rs-757266/v1

License: (c) (1) This work is licensed under a Creative Commons Attribution 4.0 International License. Read Full License

Version of Record: A version of this preprint was published at Translational Cancer Research on January 1st, 2021. See the published version at https://doi.org/10.21037/tcr-21-1841. 


\section{Abstract}

Background: The interaction between cancer cells and stromal cells has a significant contribution in tumorigenesis and tumor development, and plays an anti-tumor immune effect under the regulation of drug resistance related genes, which affects the outcome of patients. CCDC73, DLGAP1, DSEL, ESR1, and SEC14L5 were identified as drug resistance-related genes in lung cancer. However, these genes have no clear value in lung cancer in terms of expression and prognosis.

Results: The transcriptional expression level of DLGAP1 was remarkably increased in lung cancer tissues, while the transcriptional level of SEC14L5 was significantly decreased. The pathological stage of lung adenocarcinoma (LUAD) was tightly correlated with the expression of SEC14L5. The lung cancer patients with high transcription level of CCDC73 gene tended to have a good prognosis. The function of drug resistance-related genes is mainly related to RNA polymerization. Our results showed that infiltration of six types of immune cells (dendritic cells, macrophages, neutrophils, B cells, CD4+T cells, and CD8+ T cells) significantly correlated with the expression of these drug resistance-related genes.

Conclusions: Novel screening for immunotherapy targets and prognostic biomarkers in lung cancer may draw inspiration from our results.

\section{Introduction}

Lung cancer is considered to be the most commonly reported cause of malignancy and mortality from cancer in China, accounting for $21 \%$ of all cancers and $27 \%$ of all cancer-related deaths [1].

Epidemiologically, non-small-cell lung cancer (NSCLC) is responsible for the predominant number of lung cancer cases. Its fatality rate is extremely high and the early five-year survival rate does not exceed $45 \%$ [2]. It is becoming increasingly clear that the restrictions of the tumor nodal metastasis system for predicting prognosis in lung cancer patients. Thus, novel therapeutic targets such as kinases and immune checkpoint inhibitors have become the direction of exploration for many researchers $[3,4]$. However, it must be acknowledged that they are not valuable enough, and there are few therapeutic targets and prognostic biomarkers for lung cancer $[5,6]$.

Genetic alterations are considered to be an important mechanism of tumor drug resistance [7, 8]. In our previous study, through RNA sequencing analysis of lung cancer tissues of chemotherapy-sensitive patients and chemotherapy-insensitive patients, we found five significant drug resistance-related genes, including Coiled-Coil Domain-Containing Protein 73 (CCDC73), Dermatan Sulfate Epimerase Like (DSEL), DLG Associated Protein 1 (DLGAP1), Estrogen Receptor 1 (ESR1), SEC14-like 5 (SEC14L5), which had been proven to be associated with lung cancer [7-13] (Table 1). These drug resistance-related genes can directly or indirectly regulate tumor immunology and biological processes, thereby influencing tumor development, evolution, metastasis, therapeutic outcome, and patient prognosis. Therefore, these drug resistance-related genes may be potential biomarkers in lung cancer in terms of expression and prognosis. However, in the field of lung cancer, these drug resistance-related genes have not been 
sufficiently studied. In our study, we conducted a complex bioinformatics analysis of drug resistancerelated gene expression in lung cancer and made full use of the resources of public databases to provide an insightful and extensive assessment of their potential values in lung cancer in terms of expression and prognosis, thus contributing more information for clinicians to select and design individual treatment plans and predict patient prognosis with lung cancer.

Table 1

General information of 5 drug resistance-related genes.

\begin{tabular}{|lllll|}
\hline Gene & Gene_type & NCBI Gene ID & Location & Exon count \\
\hline CCDC73 & protein-coding & 493860 & $11 \mathrm{p} 13$ & 18 \\
\hline DLGAP1 & protein-coding & 9229 & $18 \mathrm{p} 11.31$ & 21 \\
\hline DSEL & protein-coding & 92126 & $18 \mathrm{q} 22.1$ & 2 \\
\hline ESR1 & protein-coding & 2099 & $6 \mathrm{q} 25.1-\mathrm{q} 25.2$ & 23 \\
\hline SEC14L5 & protein-coding & 9717 & $18 p 11.31$ & 6579 \\
\hline
\end{tabular}

\section{Methods}

\section{ONCOMINE}

ONCOMINE (https://www.oncomine.org) is a web-based bioinformatics service available for analysis of differential gene expression and prediction of co-expressed genes [14]. The expression of these drug resistance-related genes in lung cancer was assessed by extracting data. In this study, 0.05 and 2 were the threshold for $p$ value and fold change, separately. The differential expression of these drug resistancerelated genes in lung cancer was analyzed by Student's t test.

\section{GEPIA}

GEPIA (http://gepia.cancer-pku.cn/index.html), containing 9736 datasets from the GTEx and the TCGA projects, can effectively conduct online analysis and mining of cancer data for RNA sequence expression [15]. In this study, "Single Gene Analysis" was utilized for analysis of differential expression, phase of pathology and relevant prognosis of these genes. Moreover, "Multiple Gene Comparison" was used for multiple gene comparison analysis of these genes. The threshold for $p$ value was 0.05 . These genes were analyzed by Student's t test.

\section{UALCAN}

UALCAN (http://ualcan.path.uab.edu/analysis.html) functions as a versatile and robust database available for identifying biomarkers, analyzing expression profiles, and survival analysis, among others [16]. In our study, the "Expression Analysis" module, "LUAD" and "LUSC" datasets were utilized to analyze 
data of these drug resistance-related genes. Generated by the student's $t$ test, the $p$ value has a threshold value of 0.05 .

\section{cBioPortal}

cBioPortal (https://www.cbioportal.org), a user-friendly website based on numerous databases, enables visualization of cancer genomics data in multiple dimensions [17]. Genetic variation, gene network, as well as co-expression of these drug resistance-related genes were analyzed by cBioPortal. Both the $z$ scores of mRNA and protein expression were derived from the $z$ score threshold \pm 2.0 .

\section{GeneMANIA}

GeneMANIA (http://www.genemania.org), a comprehensive web resource, supplies information on genetic interactions and protein analysis, including Genetic Interactions, Pathways, and Shared protein domains [18]. In this study, protein-protein interaction (PPI) network of these drug resistance-related genes was obtained by GeneMANIA.

\section{STRING}

STRING (https://string-db.org), covering up to 5.090 thousand total organisms and 24.6 million proteins, aims to search, evaluate, and combine all available sources of PPI data using computational predictions, knowledge transfer between organisms and so on [19]. In this study, PPI network analysis of drug resistance-related genes was performed by STRING.

\section{TIMER}

TIMER (https://cistrome.shinyapps.io/timer/), an accessible and intuitive database, makes it possible to systematically assess the clinical effects of various immune cells on a variety of cancer types [20]. The statistical methods it uses have been validated using pathological estimates. In this study, "Gene Module" was used to fully explore the relationship between the expression of these genes and various immune cells. And the "Clinical Module" was used to perform the survival analysis of various types of immune cells in lung cancer.

\section{Results}

\section{Expression Patterns of Drug Resistance-Related Genes in Patients with Lung Cancer}

\section{Expression Patterns of Drug Resistance-Related Genes in Patients with Lung Cancer}

There drug resistance-related genes (including CCDC73, DLGAP1, DSEL, ESR1 and SEC14L5) were first searched with ONCOMINE, a database includes 715 datasets and 86,733 samples. The database was used to analyze differences in transcriptional levels between lung cancer and normal lung tissues (Fig. 1 
and Table 2). In comparison with normal tissues, the transcriptional levels of DLGAP1 was higher, and those of SEC14L5 were remarkably lower in lung cancer tissues. Contrary to the above results, it has been indicated that the expression level of DLGAP1 $(p=7.47 e-08)$ in lung carcinoid tumor decreased with a fold change of -34.874 [21]. The reason may be the different sources of samples. The expression level of SEC14L5 ( $p=1.42 \mathrm{e}-04)$ in lung carcinoid tumor increased, and the fold change was 3.178 in Bhattacharjee's datasets [21]. In the Garber datasets, ESR1 transcriptional levels were significantly increased in lung adenocarcinoma (LUAD) when compared with normal lung tissues [22]. However, Hou's dataset suggested that ESR1 $(p=1.78 \mathrm{e}-08)$ significantly decreased in large cell lung carcinoma [23].

Table 2

The mRNA expression levels of drug resistance-related genes in different kinds of lung cancer (ONCOMINE).

\begin{tabular}{|lllll|}
\hline Gene & Cancer Type & Fold change & $P$-value & $t$-test \\
\hline DLGAP1 & Lung Carcinoid Tumor & -34.874 & $7.47 \mathrm{E}-08$ & -6.81 \\
\hline ESR1 & Lung Adenocarcinoma & 8.770 & $4.07 \mathrm{E}-04$ & 5.958 \\
\hline ESR1 & Large Cell Lung Carcinoma & -3.558 & $1.78 \mathrm{E}-08$ & -8.015 \\
\hline SEC14L5 & Lung Carcinoid Tumor & 3.178 & $1.42 \mathrm{E}-04$ & 4.37 \\
\hline
\end{tabular}

Besides, the expression levels of these drug resistance-related genes in LUAD and lung squamous cell carcinoma (LUSC) tissues as well as in normal tissues were also tested in UALCAN. The transcriptional levels of CCDC73 $(p=3.693 e-06)$, DLGAP1 $(p=4.030 e-04)$ and ESR1 $(p=1.997 e-07)$ in LUAD tissues were significantly decreased (Fig. 2). Meanwhile, the expression levels of all genes except CCDC73 were also decreased in LUSC (Fig. 3). The relative expression levels of these drug resistance-related genes in lung cancer tissues and normal tissues were also performed for comparison (Fig. 4). The results found that among all the drug resistance-related genes we evaluated, DSEL had the highest relative expression in normal tissues. Unfortunately, no significant difference in the expression of these genes in LUAD or LUSC was found.

To search for genes closely associated with the development, evolution of lung cancer, we further evaluated the relationships between the expression of these drug resistance-related genes and the pathological stage of LUAD (Fig. 5) and LUSC (Fig. 6). The expression of SEC14L5 ( $p=0.00523$ ) showed significant correlation with the pathological stage of LUAD (Fig. 5). Unfortunately, none of the genes is significantly related to the pathological staging of LUSC (Fig. 6). These data suggested that these drug resistance-related genes might significantly lead to tumor development and progression of LUAD.

\section{The Prognostic Values of Drug Resistance-Related Genes in Patients with Lung Cancer}


The relationships between drug resistance-related genes and clinical effects of lung cancer patients was evaluated using the GEPIA database to further illuminate the potential value of these drug resistancerelated genes in lung cancer progression. LUAD patients with low DSEL $(p=0.046)$ transcription levels and high SEC14L5 $(p=0.046)$ transcription levels tended to have longer disease-free survival (DFS, Fig. 7). Unfortunately, there was no gene whose transcript levels were strongly correlated with DFS in LUSC (Fig. 8). In addition, we also evaluated the role of drug resistance-related genes in the overall survival (OS) of lung cancer patients. However, none of the genes demonstrated a significant correlation with the OS of patients with LUAD (Fig. 9). But the OS of LUSC patients with high CCDC73 transcriptional levels was remarkably prolonged (Fig. 10).

\section{Genetic Alteration, PPI Network and Interaction Analyses of These Drug Resistance-Related Genes in Patients with Lung Cancer}

A detailed and extensive molecular characterization was obtained by analysis of drug resistance-related genes to characterize their genetics and PPI. Genetic alterations in drug resistance-related genes were derived by analysis using a temporary dataset from TCGA. As a result, CCDC73, DLGAP1, DSEL, ESR1 and SEC 14 L5 were altered in $9 \%, 9 \%, 9 \%, 7 \%$, and $2.3 \%$ of the tested LUAD samples, separately (Fig. 11A). And, CCDC73, DLGAP1, DSEL, ESR1 and SEC14L5 were altered in $11 \%, 10 \%, 10 \%, 10 \%$, and $2.7 \%$ of the tested LUSC samples, separately (Fig. 11B). What followed was a further exploration of potential coexpression analysis of drug resistance-related genes. In LUAD, there was a relatively weak link between the expression of CCDC73, DLGAP1 and DSEL, and the similar link between the expression of DLGAP1 and SEC14L5 (Fig. 11C). However, in LUSC, there was a low to moderate correlation between DLGAP1 and CCDC73, DSEL and DLGAP1, and a low to moderate correlation was identified between the expression of DSEL and ESR1 (Fig. 11D). In addition, we also carried out PPI network analysis of drug resistancerelated genes and strings to explore the potential interaction between them. Unfortunately, the PPI network in the result did not gain new nodes, and thus there were no edges (Fig. 11E). The results of GeneMANIA showed that the function of these genes was mainly related to RNA polymerization, contributing to the metabolism of cancer cells (Fig. 11F).

\section{Immune Cell Infiltration of These Drug Resistance-Related Genes in Patients with Lung Cancer}

One important mechanism by which these genes affected the clinical outcome of lung cancer patients was the immune response. Therefore, TIMER database was used to conduct an extensive study on the relationship between these drug resistance-related genes and immune cell infiltration. In LUAD, both $B$ cell infiltration $(p=2.50 \mathrm{e}-3)$ and $C D 4+T$ cell infiltration $(p=7.46 \mathrm{e}-3)$ were positively associated with the expression of CCDC73 (Fig. 12A). As the expression of DSEL increased, the infiltration of $B$ cell (COR $=$ $0.137, p=2.50 e-3), C D 8+T$ cell $(C O R=0.092, p=4.34 e-2)$ and macrophage $(C O R=0.108, p=1.74 e-2)$ progressed (Fig. 12C). All six immune cell types were positively associated with the expression of ESR1 (all $p<0.05$; Fig. 12D). The expression of SEC14L5 was positively correlated with other five kinds of immune cells (all $p<0.05$ ) except CD $8+T$ cell (Fig. 12E). 
In LUSC, higher DLGAP1 expression contributed to deeper B cell infiltration (COR $=0.167, p=2.60 \mathrm{e}-4$; Fig. 13B). In addition to CD $4+T$ cells, DSEL expression and other five kinds of immune cells (all $p<0.05$; Fig. 13C). LUSC patients with higher ESR1 gene expression tended to have deeper infiltration of all studied immune cells (Fig. 13D). In LUSC, CD8 + T cells (COR $=-0.114, p=1.29 e-2)$ as well as neutrophils $(C O R=-0.111, p=1.51 e-2 ;$ Fig. 13E) were negatively correlated with SEC14L5 gene expression. The Cox proportional hazards model was utilized to further assess the degree of correlation between these drug resistance-related genes and immune cell infiltration. B cells $(p<0.001)$ and CD4 + T cells $(p=0.040)$ were remarkably correlated with the clinical effects of patients with LUAD (Table 3 ). Unfortunately, none of immune cells or these drug resistance-related genes was remarkably associated with the clinical effects of patients with LUSC lung cancer (Table 4).

Table 3

The cox proportional hazard model of drug resistance-related genes and immune cells in LUAD. (TIMER).

\begin{tabular}{|lllllll|}
\hline & coef & HR & 95\%Cl_I & $95 \%$ Cl_u & $p$-value & sig \\
\hline B_cell & -5.256 & 0.005 & 0.000 & 0.068 & 0.000 & $* \star \star$ \\
\hline CD8_Tcell & 0.202 & 1.224 & 0.195 & 7.664 & 0.829 & \\
\hline CD4_Tcell & 2.827 & 16.901 & 1.133 & 252.102 & 0.040 & $*$ \\
\hline Macrophage & 0.014 & 1.014 & 0.077 & 13.307 & 0.991 & \\
\hline Neutrophil & -0.177 & 0.838 & 0.019 & 36.589 & 0.927 \\
\hline Dendritic & -0.339 & 0.713 & 0.187 & 2.711 & 0.619 \\
\hline CCDC73 & -0.194 & 0.823 & 0.404 & 1.677 & 0.592 & \\
\hline DLGAP1 & 0.150 & 1.161 & 0.956 & 1.411 & 0.132 & \\
\hline DSEL & 0.150 & 1.162 & 0.964 & 1.401 & 0.115 & \\
\hline ESR1 & 0.045 & 1.046 & 0.914 & 1.196 & 0.516 & \\
\hline SEC14L5 & 0.088 & 1.091 & 0.733 & 1.626 & 0.667 & \\
\hline$* P<0.05, * \star P<0.01, * \star \star P<0.001 ;$ LUAD, lung adenocarcinoma; OS, overall survival. \\
\hline
\end{tabular}


Table 4

The cox proportional hazard model of drug resistance-related genes and immune cells in LUSC (TIMER).

\begin{tabular}{|llllll|}
\hline coef & HR & 95\%Cl_I & $95 \%$ Cl_u & $p$-value & sig \\
\hline B_cell & 0.933 & 2.541 & 0.226 & 28.576 & 0.450 \\
\hline CD8_Tcell & -1.213 & 0.297 & 0.051 & 1.735 & 0.178 \\
\hline CD4_Tcell & 0.371 & 1.449 & 0.118 & 17.762 & 0.772 \\
\hline Macrophage & 0.889 & 0.503 & 0.047 & 5.382 & 0.570 \\
\hline Neutrophil & 0.658 & 1.930 & 0.072 & 52.063 & 0.696 \\
\hline Dendritic & 0.607 & 1.835 & 0.448 & 7.523 & 0.399 \\
\hline CCDC73 & 0.016 & 0.984 & 0.538 & 1.802 & 0.959 \\
\hline DLGAP1 & 0.017 & 1.018 & 0.874 & 1.185 & 0.822 \\
\hline DSEL & 0.063 & 1.065 & 0.884 & 1.283 & 0.508 \\
\hline ESR1 & 0.058 & 1.060 & 0.860 & 1.306 & 0.585 \\
\hline SEC14L5 & 0.201 & 0.818 & 0.563 & 1.187 & 0.290 \\
\hline$* P<0.05, * \star P<0.01, * * * P<0.001 ;$ LUSC, lung squamous cell carcinoma; OS, overall survival. \\
\hline
\end{tabular}

\section{Discussion}

Drug resistance-related genes such as DLGAP1, ESR1, SEC14L5, DSEL, CCDC73 can make vital contributions to tumor development, tumor progression, and tumor metastasis. It has been reported that there is a correlation between these drug resistance-related genes and tumor microenvironment and tumor therapy, indicating that these drug resistance-related genes may regulate tumor progression and immunotherapy effect. Therefore, these drug resistance-related genes may be potential biomarkers in lung cancer in terms of expression and prognosis. However, the potential of these drug resistance-related genes as therapeutic targets and prognostic biomarkers in lung cancer have not been well described.

We first discussed the expression of these drug resistance-related genes in lung cancer and their relationships with pathological staging. As a result, the expression of DLGAP1 was significantly upregulated, but the expression of SEC14L5 was significantly down-regulated in lung cancer tissues. The expression of DLGAP1 was down-regulated in lung carcinoid tumor. The expression of ESR1 in LUAD tissue was up-regulated, but the expression of ESR1 in large cell lung carcinoma was down-regulated. Lung cancer patients with high CCDC73 expression tended to have longer overall survival. These data indicated that these drug resistance-related genes may contribute to the development and progression of lung cancer. 
In view of the significant differences in the expression of multiple drug resistance-related genes in lung cancer, we explored detailed and extensive molecular characteristics. Among all the mutant genes associated with the differential expression of drug resistance in LUAD and LUSC, CCDC73 was the most susceptible gene to be mutated. In contrast, SEC14L5 was the least mutated gene among all mutated genes associated with differential expression of drug resistance in LUAD and LUSC. Mutations in these genes might be associated with tumor heterogeneity and tumor drug resistance. For example, ESR1 mutations in breast cancer were an essential mechanism for anti-endocrine therapy for breast cancer [24, 25]. The development and progression of lung cancer were complex and multifaceted, and the exact mechanisms were not fully understood, but it was certain that genetic alterations were of vital importance [25]. In this study, no strong correlation was found between these drug resistance-related genes, which might suggest that these drug resistance-related genes lead to the development and progression of lung cancer by different mechanisms and pathways. These drug resistance-related genes can affect the prognosis of a wide range of tumors. It was demonstrated that CCDC73 was strongly associated with the prognosis and progression of bladder cancer [26], hepatocellular carcinoma [27] and endometrial cancer [28]. DLGAP1 is involved in the metastasis and recurrence of malignant melanoma by pathways like cell migration, extracellular matrix and cytoskeletal network, leading to a significant reduction in overall survival [28]. Inhibition of DLGAP1 expression reduces the proliferation and aggression of cancer cells and improves chemotherapy sensitivity [29]. DSEL can also function as a validated biomarker to predict overall survival in bladder cancer [30]. SEC14L5 was thought to be closely associated with rectum adenocarcinoma [31], lung cancer [7] and others. This study revealed a statistically significant relationship between the expression of SEC14L5 and the progression of LUAD.

A growing number of studies pointed to the fact that inflammatory responses and immune reactions make vital contributions in the development and progression of cancer, and could even have a significant impact on immunotherapy effect and clinical outcome [32,33]. As the main effector cells of antitumor immunity, CD8 + T cells could selectively target mutant or tumor cells and generate lethal effects through various pathways. CD $4+T$ cells not only helped CD $8+T$ and macrophages activation, but also produced cytokines and chemokines that indirectly participated in antitumor immune effects [34]. This study suggested that drug resistance-related genes could be used as an important indicator of immune status, resulting from our discovery that the expression of drug resistance-related genes was significantly correlated with the infiltration of six types of immune cells (dendritic cells, macrophages, neutrophils, $B$ cells, CD $4+T$ cells, and CD8 + T cells). Therefore, the differential expression of these drug resistancerelated genes not only correlated with lung cancer in terms of progression and prognosis, but also closely linked with the immune microenvironment, which might serve as an important biomarker to assist in tumor treatment.

There are also some limitations in this study. The immune status was only partially characterized by the analysis of the transcriptional levels, but cannot be interpreted in comprehensive details. Furthermore, it would be more persuasive if our findings were further verified in independent in vivo or in vitro biological experiments. 


\section{Conclusions}

To sum up, the resources of public databases were fully utilized to analyze the correlation between drug resistance-related genes in lung cancer selected by RNA sequencing and the development and prognosis of lung cancer. Our results could be helpful in select new immunotherapy targets and prognostic biomarkers for lung cancer, thus providing clinicians with new perspectives for designing individualized therapeutic plans and predicting survival of lung cancer patients.

\section{Abbreviations}

CCDC73, Coiled-Coil Domain-Containing Protein 73; DFS, disease-free survival; DLGAP1, DLG Associated Protein 1; DSEL, Dermatan Sulfate Epimerase Like; ESR1, Estrogen Receptor 1; LUAD, lung adenocarcinoma; LUSC, lung squamous cell carcinoma; NSCLC, non-small-cell lung cancer; OS, overall survival; PPI, protein-protein interaction; SEC14L5, SEC14-like 5

\section{Declarations}

\section{Acknowledgements}

Not applicable.

\section{Authors' contributions}

LZ and PXC designed the study and wrote the manuscript. HW and JWD performed data analysis work and aided in writing the manuscript. YYH and JWD provided administrative support. All authors read and approved the final manuscript.

\section{Funding}

This study was supported in part by a grant of National Natural Science Foundation of China (81802255), Clinical research project of Shanghai Pulmonary Hospital (FKLY20010), Young Talents in Shanghai (2019 QNBJ), 'Dream Tutor' Outstanding Young Talents Program (fkyq1901), Clinical research project of Shanghai Pulmonary Hospital (FKLY20001), Respiratory medicine, a key clinical specialty construction project in Shanghai, Promotion and application of multidisciplinary collaboration system for pulmonary non infectious diseases, Clinical Research Project of Shanghai Pulmonary Hospital (fk18005), Key Discipline in 2019 (oncology), Project of Shanghai Municipal Science and Technology Commission (Project of Municipal Science and Technology Commission), Scientific research project of Shanghai Pulmonary Hospital (fkcx1903), Shanghai Municipal Commission of Health and Family Planning (2017YQ050), Innovation Training Project of SITP of Tongji University, and key projects of leading talent (19411950300). Youth project of hospital management research fund of Shanghai Hospital Association (Q1902037).

\section{Availability of data and materials}


The datasets generated analysed during the current study are available in the databases, including Oncomine (https://www.oncomine.org), GEPIA (http://gepia.cancer-pku.cn/index.html), UALCAN (http://ualcan.path.uab.edu/analysis.html), cBioPortal (https://www.cbioportal.org), GeneMANIA (http://www.genemania.org), STRING (https://string-db.org) and Timer (https://cistrome.shinyapps.io/timer/). Further access can be obtained by contacting jwdy1994@sjtu.edu.cn.

\section{Ethics approval and consent to participate}

Not applicable.

\section{Consent for publication}

Not applicable.

\section{Competing interests}

The authors have no conflicts of interest to declare.

\section{References}

1. Goss PE, Strasser-Weippl K, Lee-Bychkovsky BL, Fan L, Li J, Chavarri-Guerra Y, Liedke PE, Pramesh CS, Badovinac-Crnjevic T, Sheikine $Y$ et al: Challenges to effective cancer control in China, India, and Russia. Lancet Oncol 2014, 15(5):489-538.

2. Almendro V, Marusyk A, Polyak K: Cellular heterogeneity and molecular evolution in cancer. Annu Rev Pathol 2013, 8:277-302.

3. Duma N, Santana-Davila R, Molina JR: Non-Small Cell Lung Cancer: Epidemiology, Screening, Diagnosis, and Treatment. Mayo Clin Proc 2019, 94(8):1623-1640.

4. Herbst RS, Morgensztern D, Boshoff C: The biology and management of non-small cell lung cancer. Nature 2018, 553(7689):446-454.

5. Jiang M, Wu C, Zhang L, Sun C, Wang H, Xu Y, Sun H, Zhu J, Zhao W, Fang Q et al: FOXP3-based immune risk model for recurrence prediction in small-cell lung cancer at stages $\mathrm{IIII}$. $\mathrm{J}$ Immunother Cancer 2021, 9(5).

6. He Y, Yu H, Rozeboom L, Rivard CJ, Ellison K, Dziadziuszko R, Suda K, Ren S, Wu C, Hou L et al: LAG3 Protein Expression in Non-Small Cell Lung Cancer and Its Relationship with PD-1/PD-L1 and Tumor-Infiltrating Lymphocytes. J Thorac Oncol 2017, 12(5):814-823.

7. Zhang S, Thakur A, Liang Y, Wang T, Gao L, Yang T, Li Y, Geng T, Jin T, Chen T et al: Polymorphisms in C-reactive protein and Glypican- 5 are associated with lung cancer risk and Gartrokine-1 influences Cisplatin-based chemotherapy response in a Chinese Han population. Dis Markers 2015, 2015:824304. 
8. He Y, Song L, Wang H, Chen P, Liu Y, Sun H, Li X, Dang S, Liu G, Liu X et al: Mutational Profile Evaluates Response and Survival to First-Line Chemotherapy in Lung Cancer. Adv Sci (Weinh) 2021, 8(4):2003263.

9. Yang C, Ren J, Li B, Zhang D, Ma C, Cheng C, Sun Y, Fu L, Shi X: Identification of clinical tumor stages related mRNAs and miRNAs in cervical squamous cell carcinoma. Pathol Res Pract 2018, 214(10):1638-1647.

10. Teng C, Huang G, Luo Y, Pan Y, Wang H, Liao X, Li Y, Yang J: Differential long noncoding RNAs expression in cancer-associated fibroblasts of non-small-cell lung cancer. Pharmacogenomics 2019, 20(3):143-153.

11. Namani A, Cui QQ, Wu Y, Wang H, Wang XJ, Tang X: NRF2-regulated metabolic gene signature as a prognostic biomarker in non-small cell lung cancer. Oncotarget 2017, 8(41):69847-69862.

12. Li J, Ji Z, Luo X, Li Y, Yuan P, Long J, Shen N, Lu Q, Zeng Q, Zhong R et al: Urinary bisphenol A and its interaction with ESR1 genetic polymorphism associated with non-small cell lung cancer: findings from a case-control study in Chinese population. Chemosphere 2020, 254:126835.

13. Kuang P, Chen P, Wang L, Li W, Chen B, Liu Y, Xu Y, Wang H, Zhao S, Ye L et al: RNA sequencing analysis of small cell lung cancer reveals candidate chemotherapy insensitivity long noncoding RNAs and microRNAs. Ann Transl Med 2020, 8(4):121.

14. Rhodes DR, Yu J, Shanker K, Deshpande N, Varambally R, Ghosh D, Barrette T, Pandey A, Chinnaiyan AM: ONCOMINE: a cancer microarray database and integrated data-mining platform. Neoplasia 2004, 6(1):1-6.

15. Tang Z, Li C, Kang B, Gao G, Li C, Zhang Z: GEPIA: a web server for cancer and normal gene expression profiling and interactive analyses. Nucleic Acids Res 2017, 45(W1):W98-W102.

16. Chandrashekar DS, Bashel B, Balasubramanya SAH, Creighton CJ, Ponce-Rodriguez I, Chakravarthi B, Varambally S: UALCAN: A Portal for Facilitating Tumor Subgroup Gene Expression and Survival Analyses. Neoplasia 2017, 19(8):649-658.

17. Gao J, Aksoy BA, Dogrusoz U, Dresdner G, Gross B, Sumer SO, Sun Y, Jacobsen A, Sinha R, Larsson E et al: Integrative analysis of complex cancer genomics and clinical profiles using the cBioPortal. Sci Signal 2013, 6(269):pl1.

18. Warde-Farley D, Donaldson SL, Comes O, Zuberi K, Badrawi R, Chao P, Franz M, Grouios C, Kazi F, Lopes CT et al: The GeneMANIA prediction server: biological network integration for gene prioritization and predicting gene function. Nucleic Acids Res 2010, 38(Web Server issue):W214-220.

19. Szklarczyk D, Gable AL, Lyon D, Junge A, Wyder S, Huerta-Cepas J, Simonovic M, Doncheva NT, Morris JH, Bork $\mathrm{P}$ et al: STRING v11: protein-protein association networks with increased coverage, supporting functional discovery in genome-wide experimental datasets. Nucleic Acids Res 2019, 47(D1):D607-D613.

20. Li T, Fan J, Wang B, Traugh N, Chen Q, Liu JS, Li B, Liu XS: TIMER: A Web Server for Comprehensive Analysis of Tumor-Infiltrating Immune Cells. Cancer Res 2017, 77(21):e108-e110. 
21. Bhattacharjee A, Richards WG, Staunton J, Li C, Monti S, Vasa P, Ladd C, Beheshti J, Bueno R, Gillette $\mathrm{M}$ et al: Classification of human lung carcinomas by mRNA expression profiling reveals distinct adenocarcinoma subclasses. Proc Natl Acad Sci U S A 2001, 98(24):13790-13795.

22. Garber ME, Troyanskaya OG, Schluens K, Petersen S, Thaesler Z, Pacyna-Gengelbach M, van de Rijn M, Rosen GD, Perou CM, Whyte RI et al: Diversity of gene expression in adenocarcinoma of the lung. Proc Natl Acad Sci U S A 2001, 98(24):13784-13789.

23. Hou J, Aerts J, den Hamer B, van ljcken W, den Bakker M, Riegman P, van der Leest C, van der Spek $P$, Foekens JA, Hoogsteden $\mathrm{HC}$ et al: Gene expression-based classification of non-small cell lung carcinomas and survival prediction. PLoS One 2010, 5(4):e10312.

24. Jeselsohn R, Buchwalter G, De Angelis C, Brown M, Schiff R: ESR1 mutations-a mechanism for acquired endocrine resistance in breast cancer. Nat Rev Clin Oncol 2015, 12(10):573-583.

25. Yap NY, Rajandram R, Ng KL, Pailoor J, Fadzli A, Gobe GC: Genetic and Chromosomal Aberrations and Their Clinical Significance in Renal Neoplasms. Biomed Res Int 2015, 2015:476508.

26. Liu L, Zhong X, Cui H, Zhang H, Wang L, Liu Y: Identification of an Individualized Prognostic Signature Based on the RWSR Model in Early-Stage Bladder Carcinoma. Biomed Res Int 2020, 2020:9186546.

27. Gao HJ, Chen YJ, Zuo D, Xiao MM, Li Y, Guo H, Zhang N, Chen RB: Quantitative proteomic analysis for high-throughput screening of differential glycoproteins in hepatocellular carcinoma serum. Cancer Biol Med 2015, 12(3):246-254.

28. O'Mara TA, Glubb DM, Amant F, Annibali D, Ashton K, Attia J, Auer PL, Beckmann MW, Black A, Bolla MK et al: Identification of nine new susceptibility loci for endometrial cancer. Nat Commun 2018, 9(1):3166.

29. Rendleman J, Shang S, Dominianni C, Shields JF, Scanlon P, Adaniel C, Desrichard A, Ma M, Shapiro $\mathrm{R}$, Berman $\mathrm{R}$ et al: Melanoma risk loci as determinants of melanoma recurrence and survival. $J$ Transl Med 2013, 11:279.

30. Lin J, Yang J, Xu X, Wang Y, Yu M, Zhu Y: A robust 11-genes prognostic model can predict overall survival in bladder cancer patients based on five cohorts. Cancer Cell Int 2020, 20:402.

31. Huang W, Li G, Wang Z, Zhou L, Yin X, Yang T, Wang P, Teng X, Feng Y, Yu H: A Ten-N(6)Methyladenosine (m(6)A)-Modified Gene Signature Based on a Risk Score System Predicts Patient Prognosis in Rectum Adenocarcinoma. Front Oncol 2020, 10:567931.

32. Bindea G, Mlecnik B, Tosolini M, Kirilovsky A, Waldner M, Obenauf AC, Angell H, Fredriksen T, Lafontaine $L$, Berger $A$ et al: Spatiotemporal dynamics of intratumoral immune cells reveal the immune landscape in human cancer. Immunity 2013, 39(4):782-795.

33. Liu X, Wu S, Yang Y, Zhao M, Zhu G, Hou Z: The prognostic landscape of tumor-infiltrating immune cell and immunomodulators in lung cancer. Biomed Pharmacother 2017, 95:55-61.

34. Lin P, Guo YN, Shi L, Li XJ, Yang H, He Y, Li Q, Dang YW, Wei KL, Chen G: Development of a prognostic index based on an immunogenomic landscape analysis of papillary thyroid cancer. Aging (Albany NY) 2019, 11(2):480-500. 

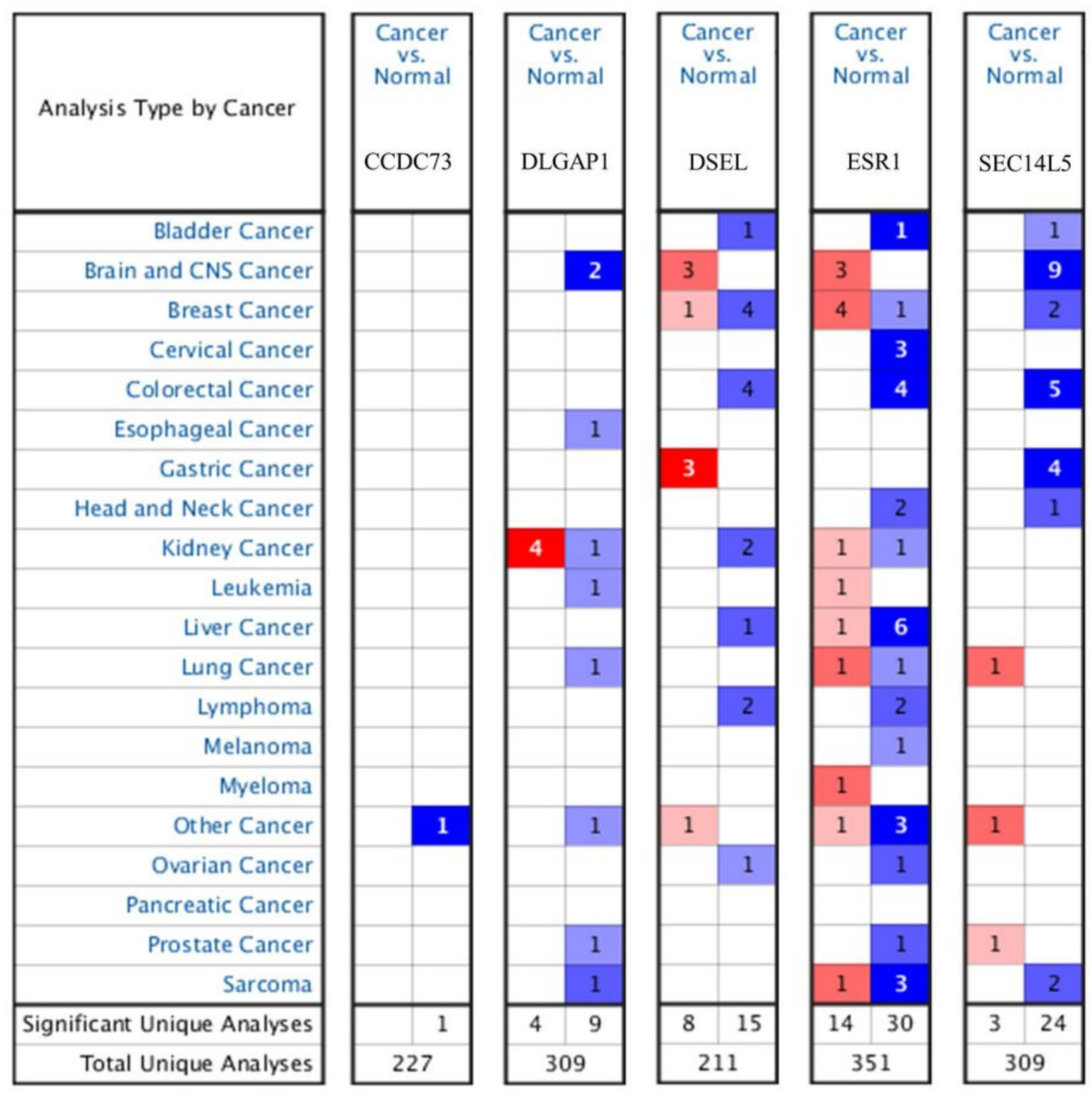

\section{$\square \stackrel{510}{\square} \square \square \square \square \square$}

Cell color is determined by the best gene rank percentile for the analyses within the cell.

\section{Figure 1}

The mRNA expression levels of these drug resistance-related genes in lung cancer (ONCOMINE). The numbers in the red (mRNA over expression) or blue (mRNA downregulated expression) blocks represent statistically significant datasets. 


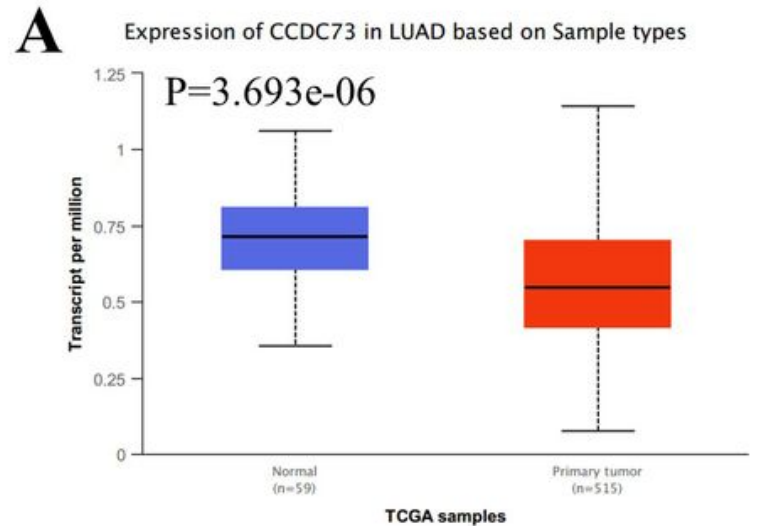

C

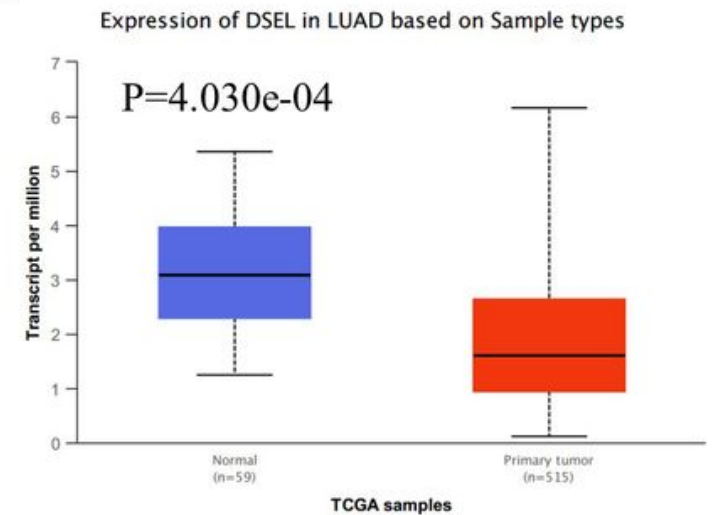

$\mathbf{E}$

Expression of SEC14L5 in LUAD based on Sample types

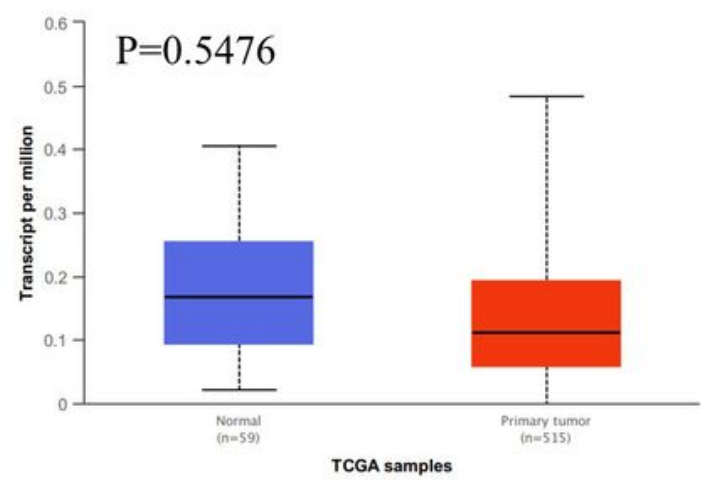

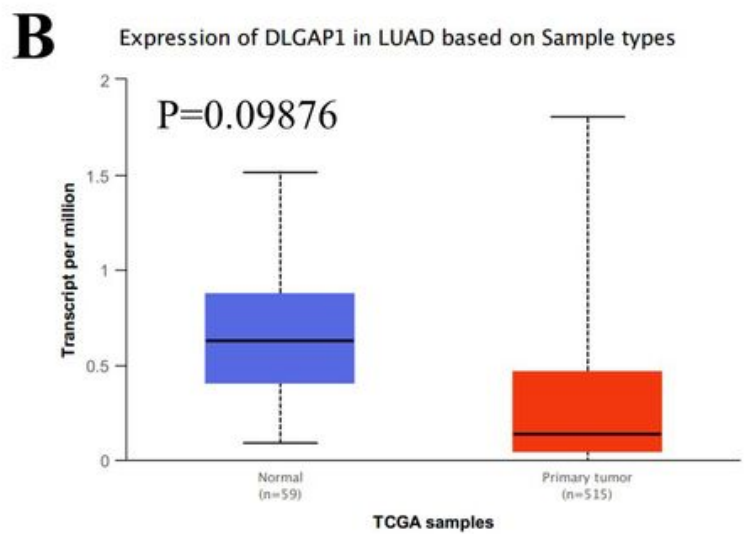

D

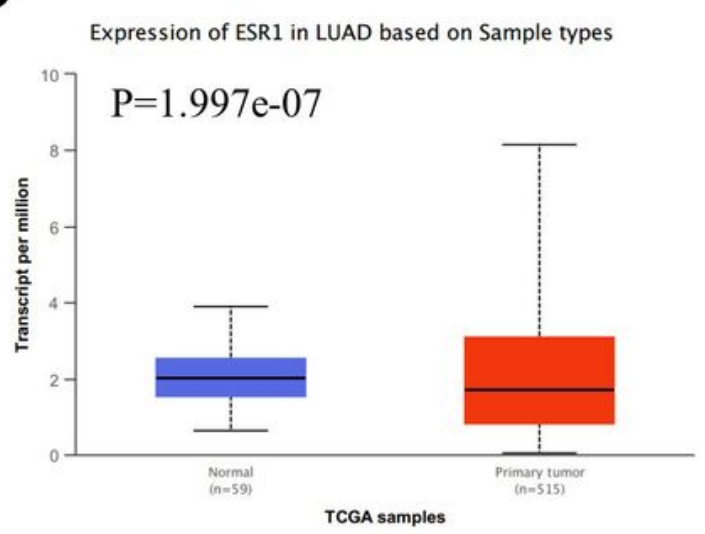

\section{Figure 2}

The mRNA expression levels of these drug resistance-related genes in LUAD (UALCAN). The threshold of p value was 0.05. (A) CCDC73, (B) DLGAP1, (C) DSEL, (D) ESR1, and (E) SEC14L5; LUAD, lung adenocarcinoma. 


\section{Image not available with this version}

\section{Figure 3}

The mRNA expression levels of these drug resistance-related genes in LUSC (UALCAN). The threshold of $p$ value was 0.05. (A) CCDC73, (B) DLGAP1, (C) DSEL, (D) ESR1, and (E) SEC14L5; LUSC, lung squamous cell carcinoma.

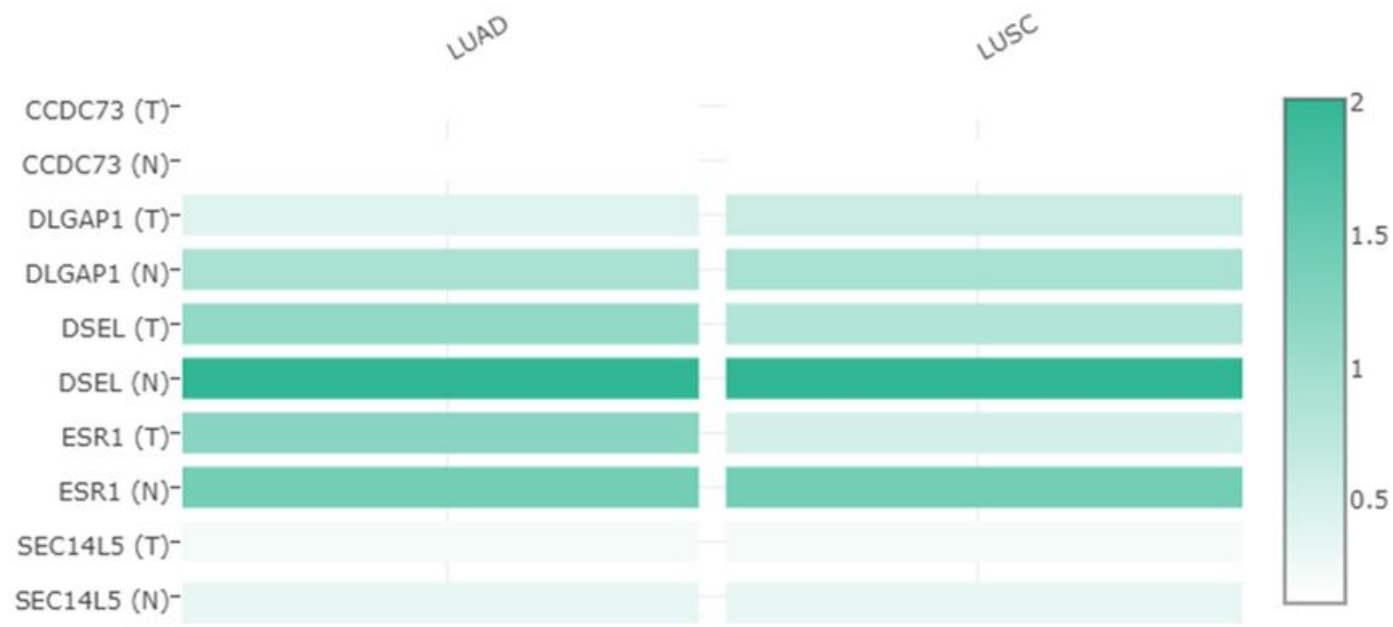

\section{Figure 4}

The relative level of these drug resistance-related genes in LUAD (left) and LUSC (right). T, tumor tissues; $\mathrm{N}$, normal tissues; LUAD, lung adenocarcinoma; LUSC, lung squamous cell carcinoma. 

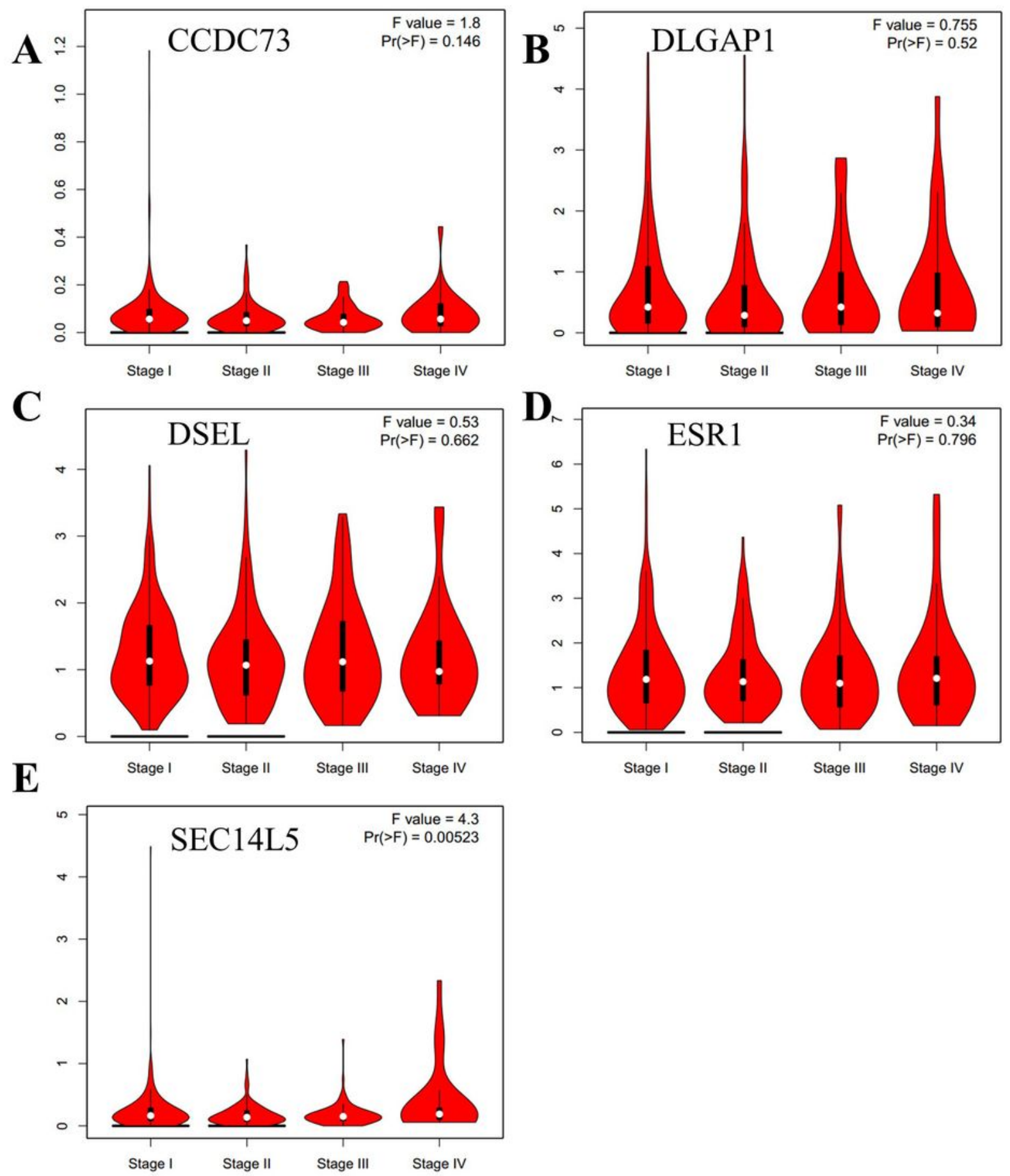

\section{Figure 5}

The correlation between drug resistance-related genes and the pathological stage of LUAD patients (GEPIA). *P < 0.05. (A) CCDC73, (B) DLGAP1, (C) DSEL, (D) ESR1, and (E) SEC14L5; LUAD, lung adenocarcinoma. 

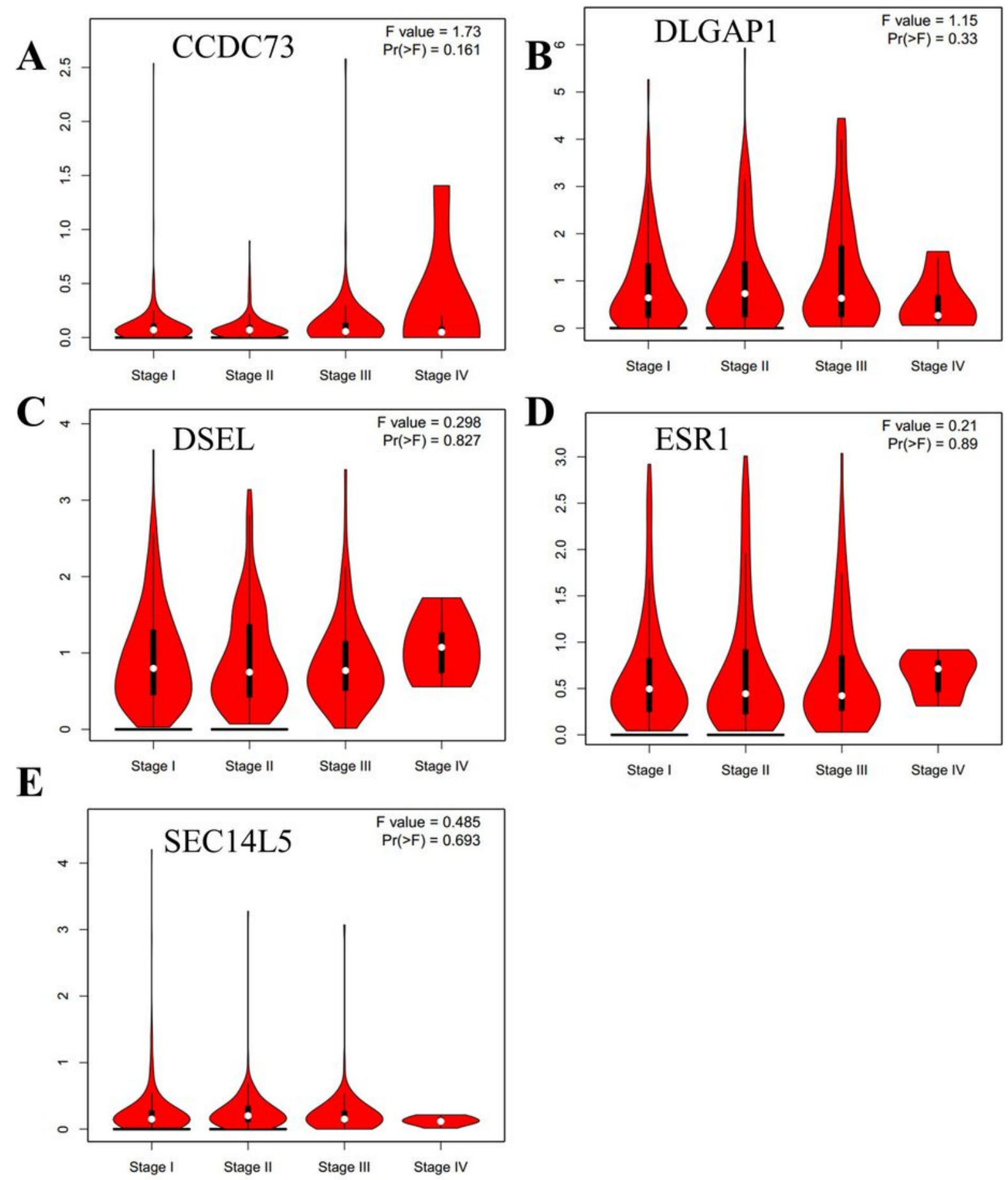

Figure 6

The correlation between drug resistance-related genes and the pathological stage of LUSC patients (GEPIA). *P < 0.05. (A) CCDC73, (B) DLGAP1, (C) DSEL, (D) ESR1, and (E) SEC14L5; LUSC, lung squamous cell carcinoma. 

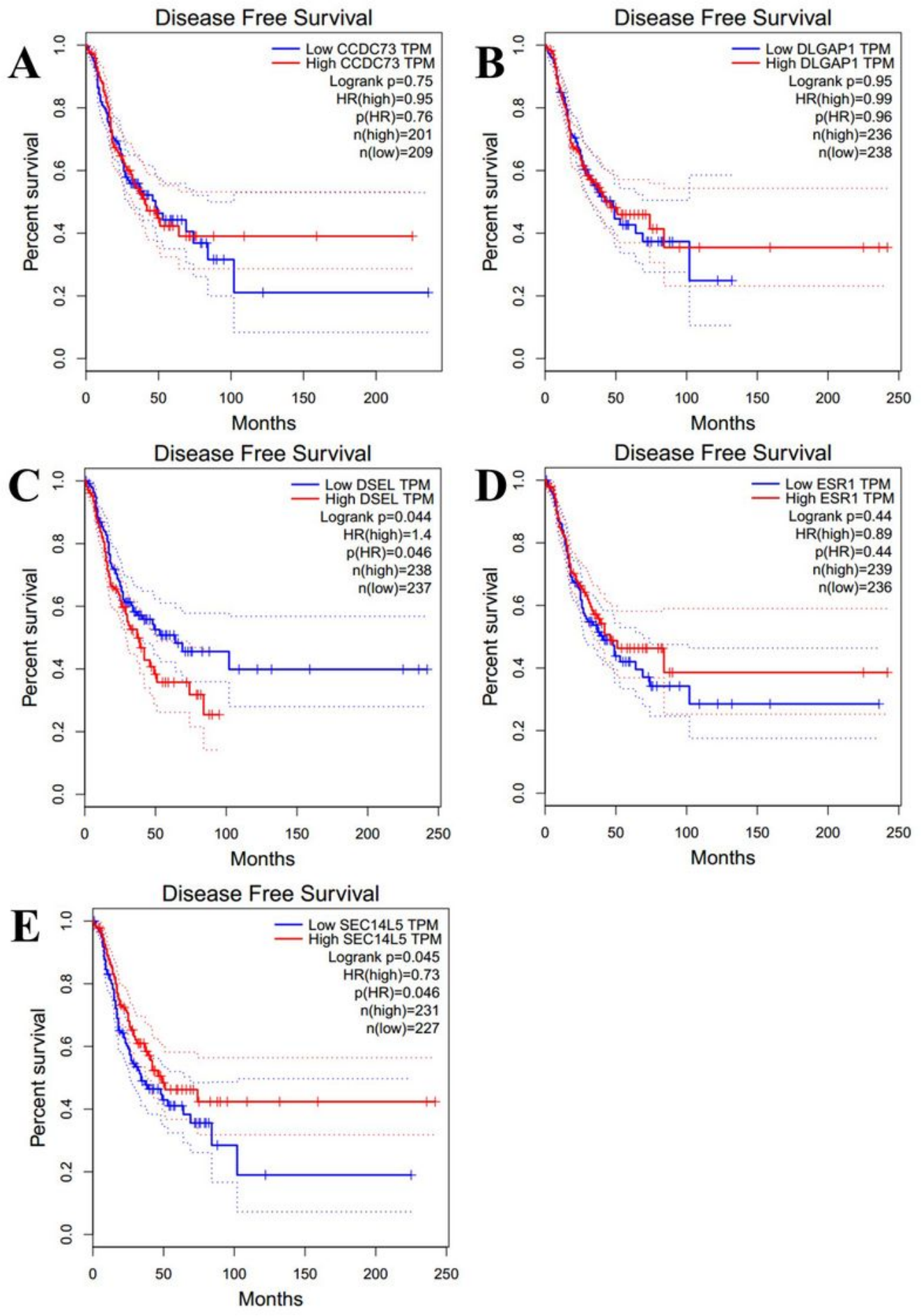

\section{Figure 7}

The prognostic value of drug resistance-related genes in LUAD patients in the DFS curve (GEPIA). The DFS curve of (A) CCDC73, (B) DLGAP1, (C) DSEL, (D) ESR1, and (E) SEC14L5 in LUAD; DFS, disease-free survival; LUAD, lung adenocarcinoma. 

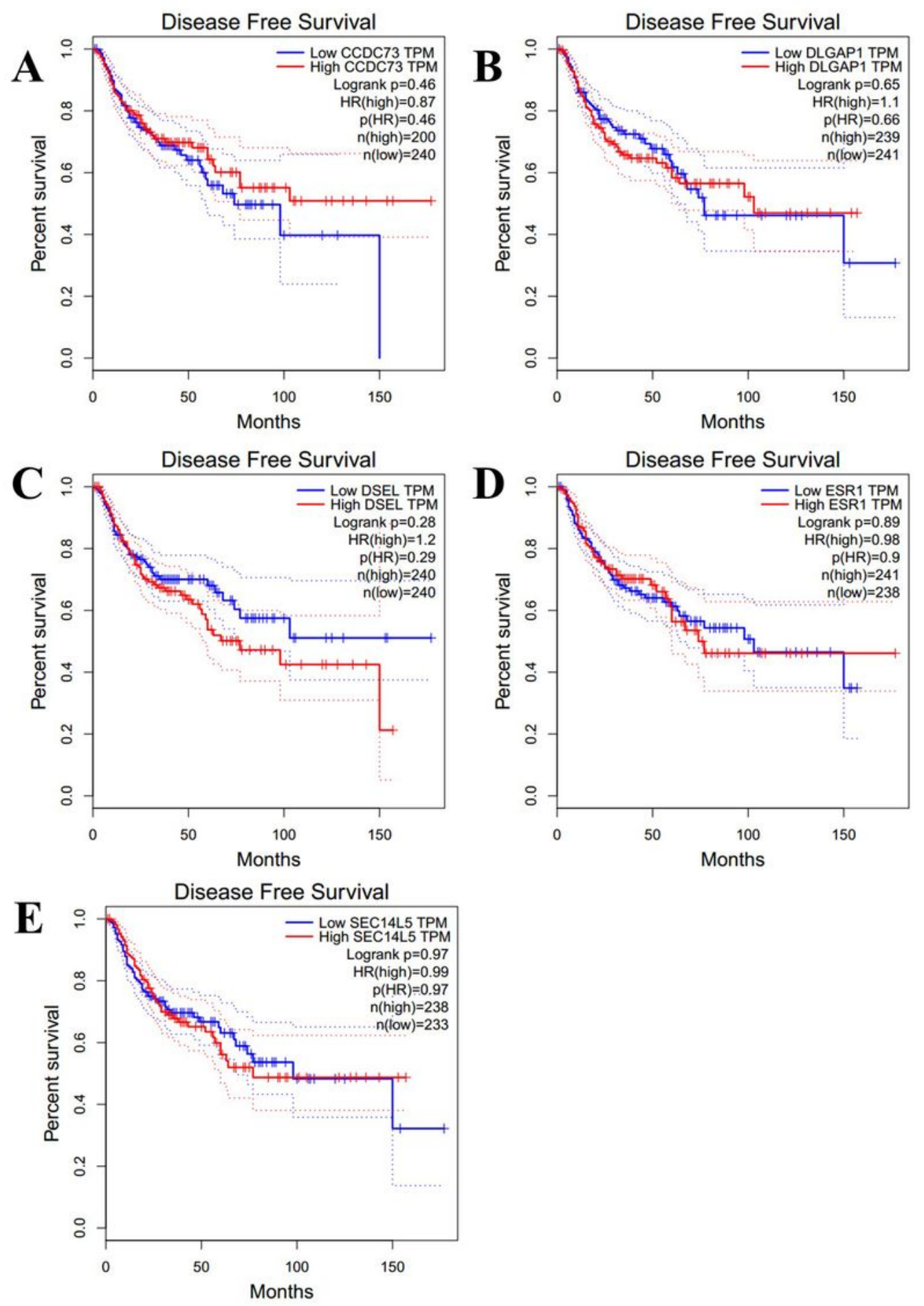

\section{Figure 8}

The prognostic value of drug resistance-related genes in LUSC patients in the DFS curve (GEPIA). The DFS curve of (A) CCDC73, (B) DLGAP1, (C) DSEL, (D) ESR1, and (E) SEC14L5 in LUSC; DFS, disease-free survival; LUSC, lung squamous cell carcinoma. 

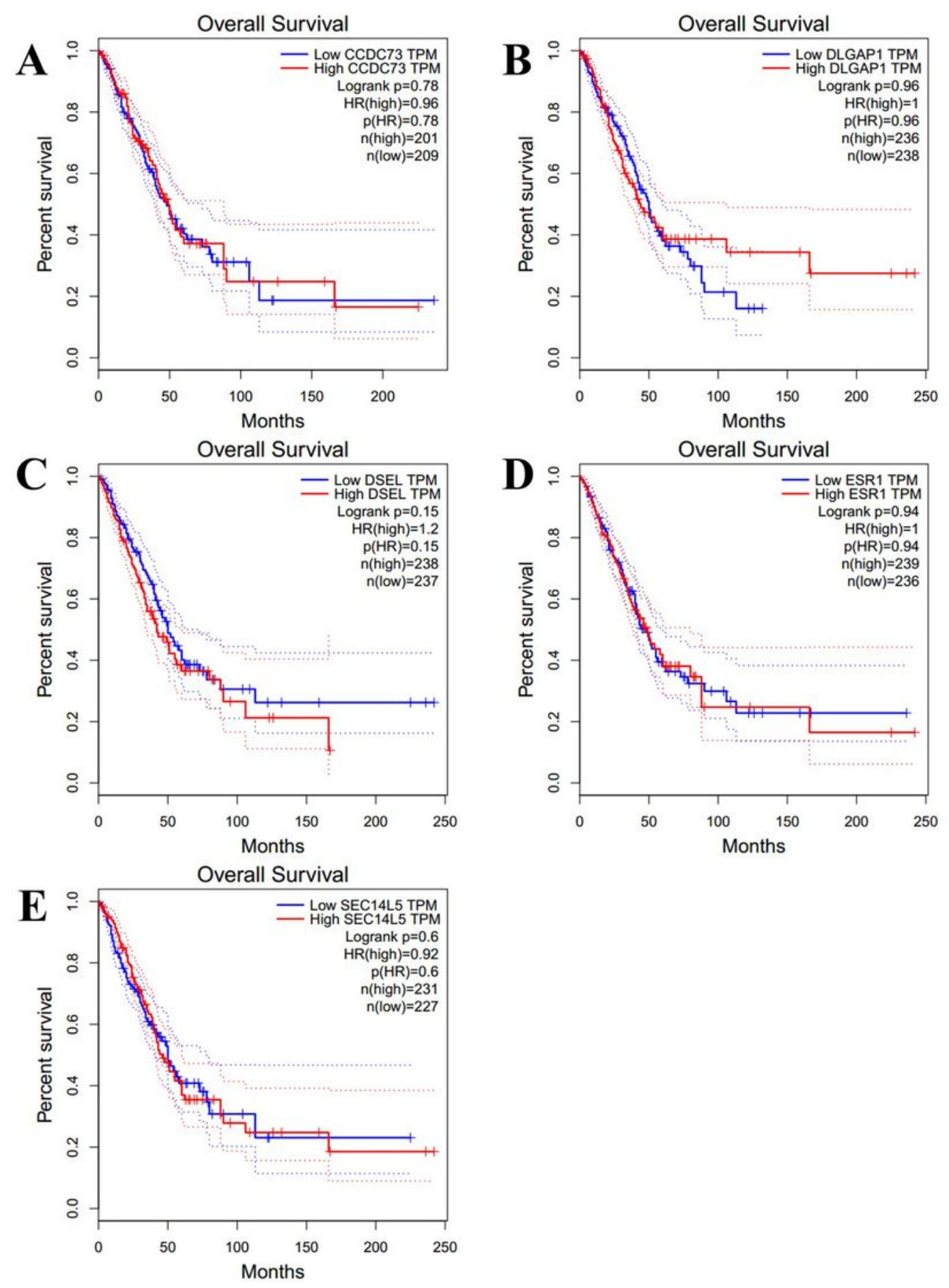

\section{Figure 9}

The prognostic value of drug resistance-related genes in LUAD patients in the OS curve (GEPIA). The overall survival curve of (A) CCDC73, (B) DLGAP1, (C) DSEL, (D) ESR1, and (E) SEC14L5 in LUAD; LUAD, lung adenocarcinoma; OS, overall survival. 

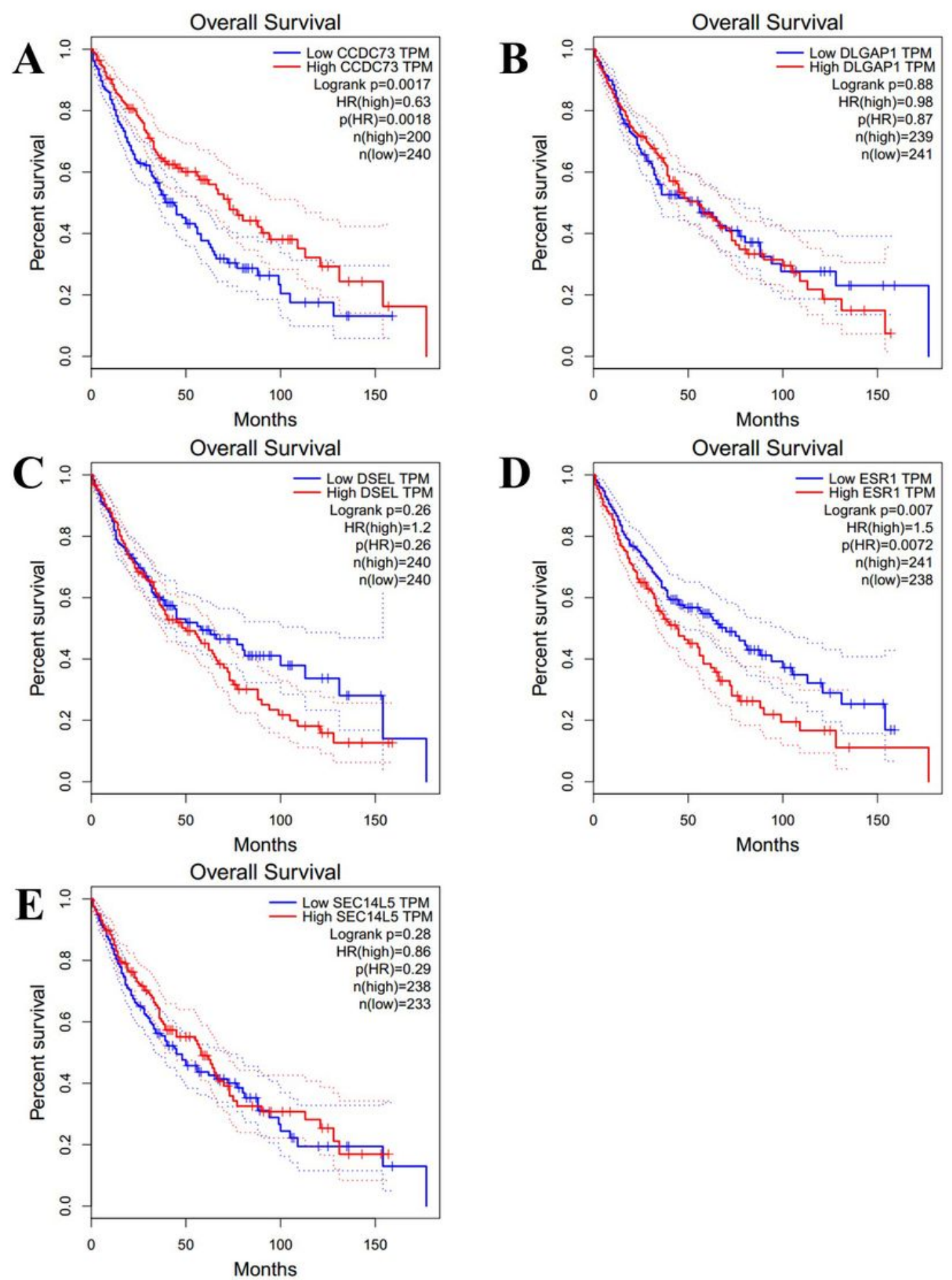

\section{Figure 10}

The prognostic value of different expressed drug resistance-related genes in LUSC patients in the OS curve (GEPIA). The overall survival curve of (A) CCDC73, (B) DLGAP1, (C) DSEL, (D) ESR1, and (E) SEC14L5 in LUSC; LUSC, lung squamous cell carcinoma; OS, overall survival. 
A

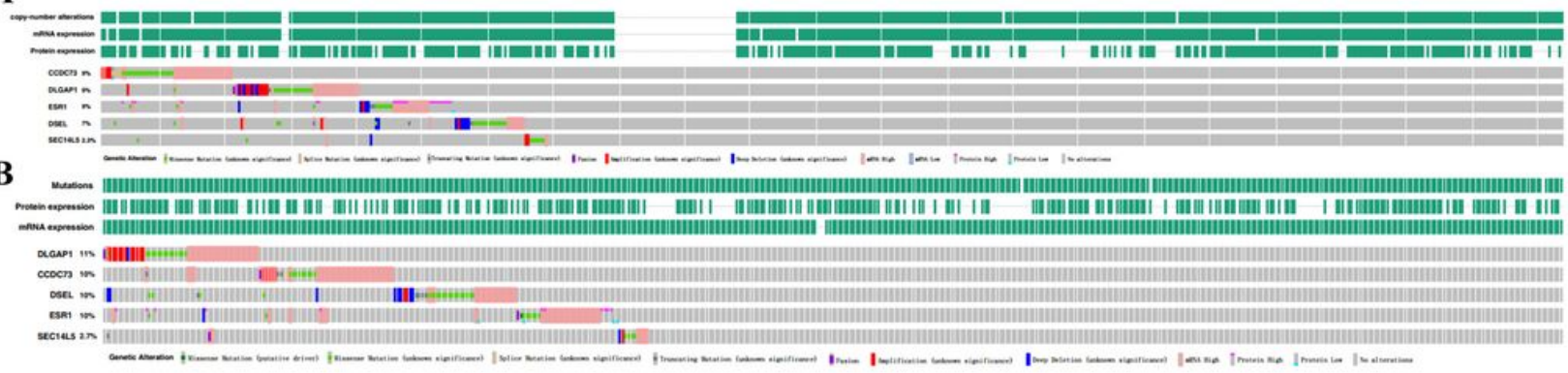

\begin{tabular}{|c|c|c|c|c|c|}
\hline & CCDC73 & DLGAP1 & DSEL & ESR1 & SEC14L5 \\
\hline CCDC73 & 1 & 0.147 & 0.162 & -0.0326 & 0.0399 \\
\hline DLGAP1 & 0.147 & 1 & 0.132 & 0.0431 & 0.183 \\
\hline DSEL & 0.162 & 0.132 & 1 & 0.0126 & -0.0163 \\
\hline ESR1 & -0.0326 & 0.0431 & 0.0126 & 1 & -0.0448 \\
\hline SEC14L5 & 0.0399 & 0.183 & -0.0163 & -0.0448 & 1 \\
\hline
\end{tabular}

D

\begin{tabular}{|c|c|c|c|c|c|}
\hline & CCDC73 & DLGAP1 & DSEL & ESR1 & SEC14L5 \\
\hline CCDC73 & 1 & 0.0404 & -0.0515 & -0.0026 & 0.0112 \\
\hline DLGAP1 & 0.0404 & 1 & 0.146 & -0.121 & 0.122 \\
DSEL & -0.0515 & 0.146 & 1 & 0.14 & -0.022 \\
ESR1 & -0.0026 & -0.121 & 0.14 & 1 & -0.13 \\
\hline SEC14L5 & 0.0112 & 0.122 & -0.022 & -0.13 & 1 \\
\hline
\end{tabular}

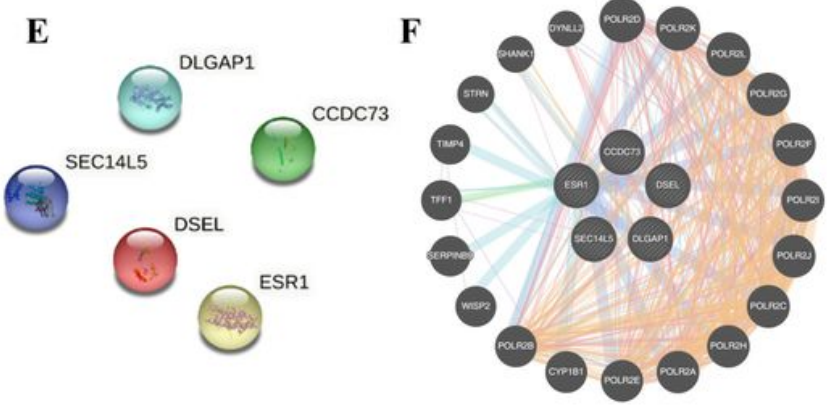

\section{Figure 11}

Genetic alteration, PPI network and interaction analyses of drug resistance-related genes in lung cancer patients. (A, B) The description of genetic alterations in different expressed drug resistance-related genes in LUAD (up) and LUSC (bottom) patients. (C, D) The correlation heat map of different expressed drug resistance-related genes in LUAD (up) and LUSC (bottom) patients. (E, F) PPI network of different expressed drug resistance-related genes; LUAD, lung adenocarcinoma; LUSC, lung squamous cell carcinoma. 


\section{A}
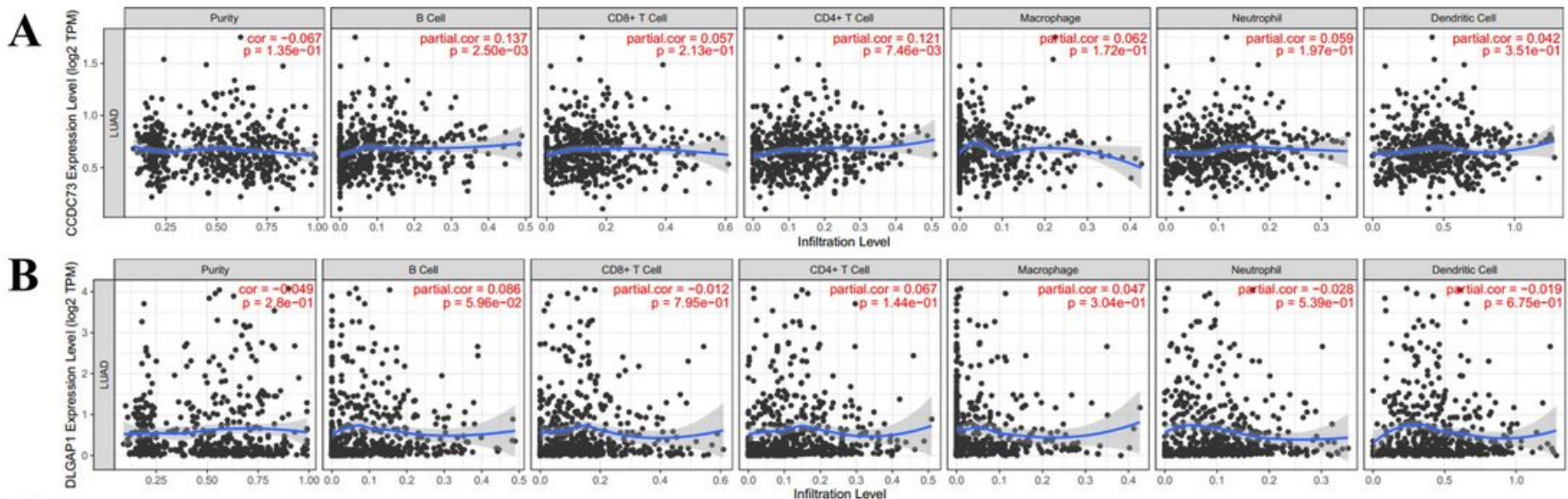

C
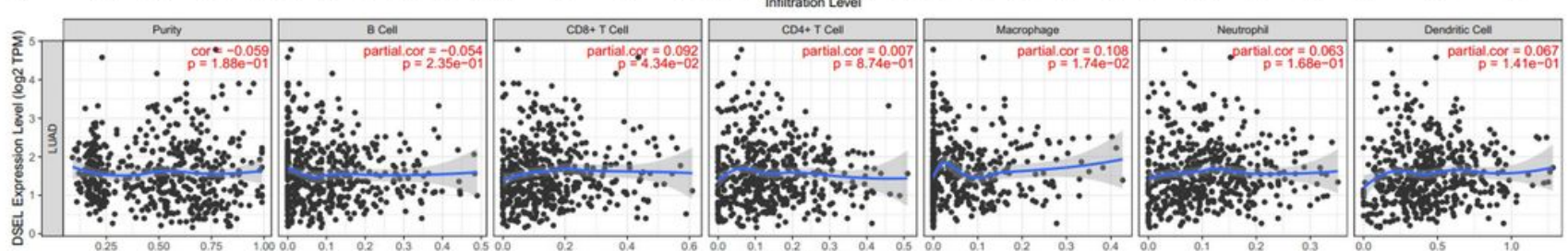

D
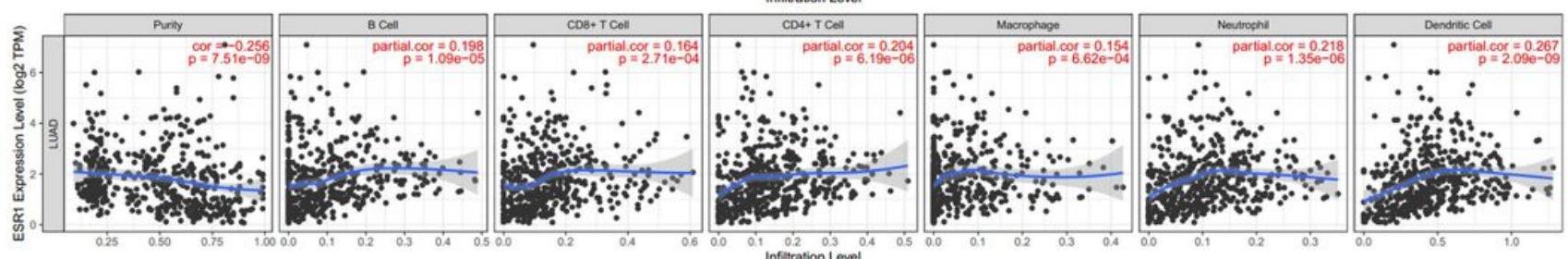

$\mathbf{E}$
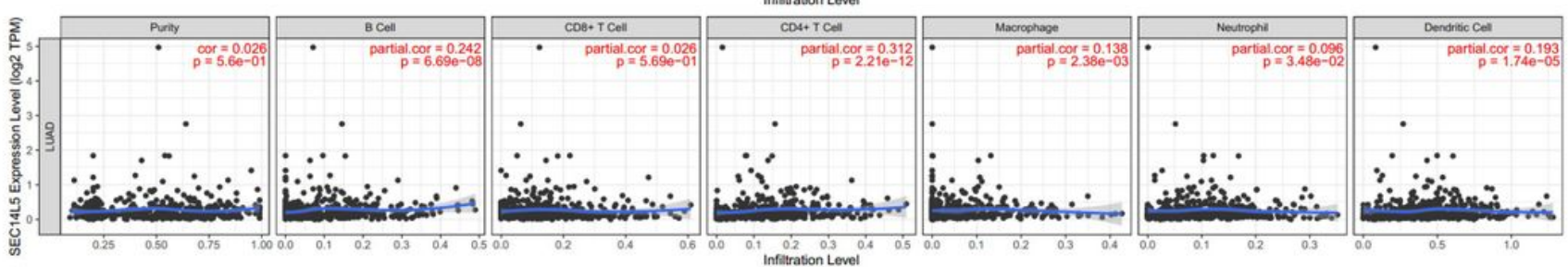

Figure 12

The correlation between different expressed drug resistance-related genes and six tumor-infiltrating immune cells in LUAD (TIMER). The correlation between the abundance of immune cell and the expression of (A) CCDC73, (B) DLGAP1, (C) DSEL, (D) ESR1, and (E) SEC14L5; LUAD, lung adenocarcinoma. 

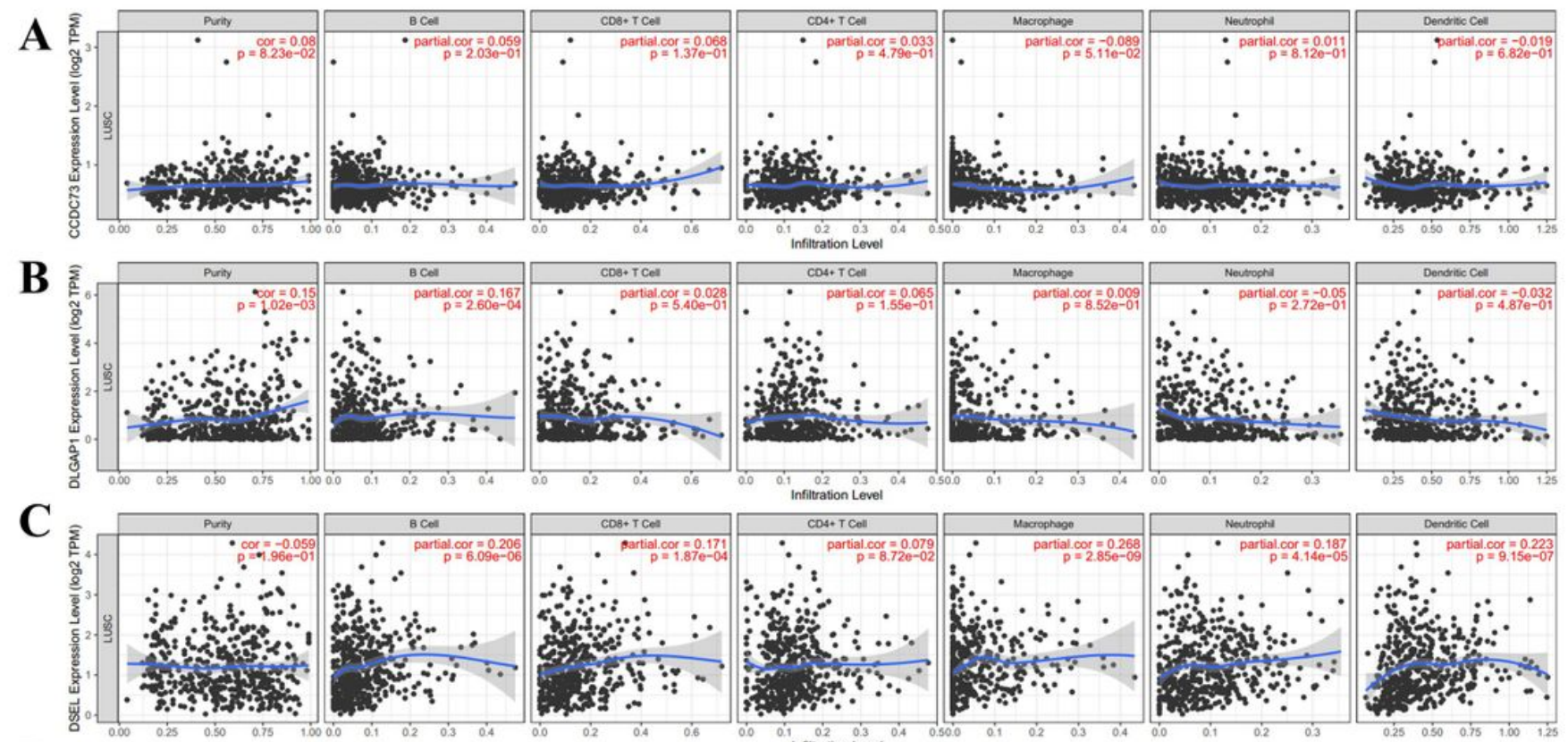

D
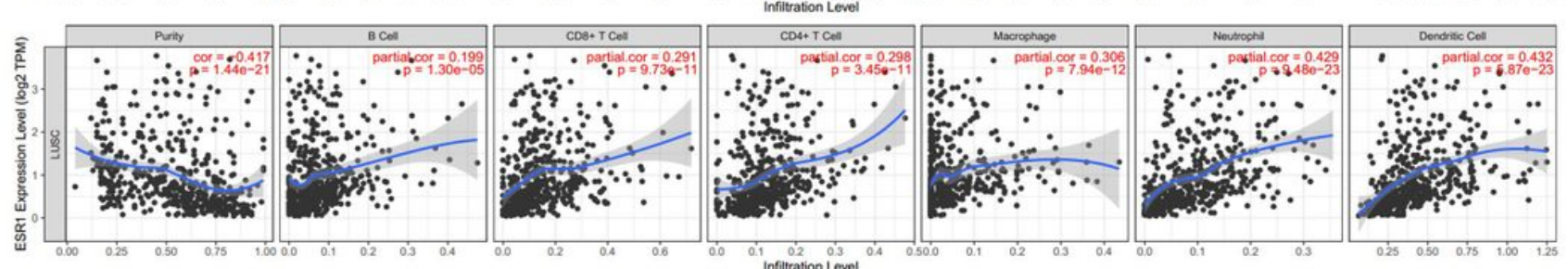

$\mathbf{E}$

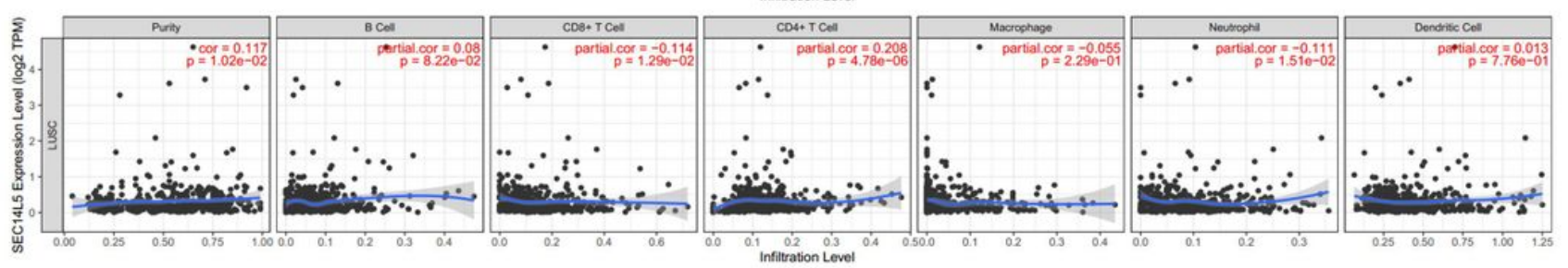

Figure 13

The correlation between drug resistance-related genes and six tumor-infiltrating immune cells in LUSC (TIMER). The correlation between the abundance of immune cell and the expression of (A) CCDC73, (B) DLGAP1, (C) DSEL, (D) ESR1, and (E) SEC14L5 in LUSC; LUSC, lung squamous cell carcinoma. 